\title{
The Role Of School In Gender Socialization
}

\author{
PhD Candidate Erjona Molla \\ University of Tirana
}

\begin{abstract}
The family and the school are the two main pillars that influence the child during the process of growth, but also play a major role in the socialization of gender roles in the way they organize the environment for the child. The development of gender roles begins at birth. The children are exposed to many factors that influence their attitudes and behavior with regard to gender roles. These attitudes and behaviors are usually taught at home and then reinforced by the peers of the child and the school experience. In everyday life we tend to believe that boys are more favored in school since they are seen as "strong", in fact the discrimination exists but it is a discrimination to the detriment of boys. Boys compared with girls have a higher tendence to be class repeaters, also they have a higher tendency to drop out of school. In some cultures, school attendance by boys is limited because of gender role expectations. Because they are "strong" they need to work to bring revenues in the family. The school remains one of the social institutions that can and should build a deliberate gender education and a proper socialization to the benefit of society. The gender education should play an important role in the educational system.
\end{abstract}

Keywords: Gender discrimination, gender role, gender education, gender socialization

\section{Introduction}

The process of socialization is a very important process for both the individual and for the society. For centuries people tried to give answers to the question, whether what defines human beings are natural features (inherited) or social features (formed through contacts with other people and through the collaboration with them). society?

Are we individuals created by nature or individuals created by

For this, were studied identical twins, also have been conducted other studies with children, who are grown isolated from people. If two identical twins grow far apart then their development is completely different. Isolated 
children, whose formation was enabled only by the language, they have no experience with other people and can not understand the relationships between people.

So, what makes each of us human is society.

In fact, women as well as men, act and think in the context of images that have created about what is masculine and feminine, always connected with culture.

The interplanetary theory of gender tells us that boys and girls are fundamentally and categorically different, that boys excel in science and math, play violently in the playground, and shout out in class; that girls, on the other hand, sit quietly, speak softly, play gingerly, and excel in foreing languages and literature. At the same time, of course, we sit in the same classroom, read the same books, listen to the same teachers, and are supposedly graded by the same criteria.

Our gender experiences begin before we go to school. At the moment when we begin the first class, we learn more than the alphabet, learn more than syllables, more than mathematics and literature. We learn something more, what it means to be a man or a woman.

\section{The process of gender socialization in schools}

The main question raised in this article is what is socialization?

The process through which people learn and acquire the characteristics of the social group to which they belong is called socialization. The socialization of individuals enables the preservation and sustainability of the characteristics, values and social norms because these are taught and transmitted from one generation to another. The American sociologist Peter Berger wrote: what happens during the socialization is that the social world is internalized on the child. The society does not only control our movements but also provides our identity, thoughts and emotions.

The gender equality is a value of socialization. The gender socialization begins before the child come to life. With gender socialization we understand the processes through which individuals, based on their sex learn to behave, feel, think according to the forms that in the social aspect are appropriate for their sex that they see the world in the light of gender differences, where every individual, female or male is placed and set objects and beings that surround him, within a social and symbolic hierarchy between men and women, between masculinity and femininity.

The school is a very important institution that influences the child's socialization. In school except the curricula, the students learn also that executives are more men and the women are in lower positions. In general, teachers do not behave the same with girls and with boys. They expect from 
girls to be more polite, while the boys are expected to be more oblivious. In addition, teachers attribute to the girls the progress of their efforts while they attribute to the boys the intellectual capacity and talent, even in case of failure they think that boys have not exploited their intellectual capacity.

In the primary school, the boys are four times more likely to be sent to child psychologists and more likely to be diagnosed with dyslexia and attention deficit disorder (ADD) than girls. Starting in primary school and continuing throughout their schooling, boys take fewer notes and graduations; they are more likely to repeat a grade. Boys are nine times more likely than girls to be diagnosed as hyperactive; boys represent 58 percent of those who attend classes for special education. Nearly three quarters of all school suspensions are boy's suspensions. In adolescence, boys are more likely to drop out, to repeat class and misbehave in class. Their self-esteem also falls during adolescence - admittedly, not so much as the self-esteem of girls, but it falls.

These data are often used to suggest that boys, not girls, are victims of a significant gender discrimination in schools. After all, what happens to boys in schools? They must sit in silence, slumber, raise their hands, be convinced - all these are a tremendous violation for their "natural" liveliness, inspired by testosterone, insubordinate. "Schools in most of the cases are led by women for girls. To take a second or third grade boy with free spirit and to expect him to behave like a school girl is asking too much," comments Christina Hoff Sommers, author of Fight against boys. The effect of education is "pathological boyhood." "On average, boys were physically less peaceful and more impulsive (than girls)," says school consultant Michael Thompson. "We need to accept the physical needs of boys and to meet them." The class, as the workplace is an institution of the public sphere and when women enter the public sphere, they often have to dress and act "masculine" in order to be taken seriously as competent and capable. A recent advertising campaign for children's clothes Polo by Ralph Lauren took pictures of little girls, aged five or six years, with T-shirts, sports jackets and Oxford ties without buttons. Who is being feminized and who is being masculinised? As we have seen, there is little evidence that boys' aggression is biologically based. Rather, it is understood that the negative consequences of the aggression of boys are mainly a social bioproduct of the exaggeration of healthy and pleasurable, strong and messy games. And it is exaggerated by boys so that they can adapt better to the other guys, they agree perfectly with the expectations of their peers. Rather than glorify "the boys culture", we can ask instead about the experience when boys cease to be boys and boys begin to stand and show their masculinity in the assessing eyes of other boys. At that moment we can find a psychological "disconnect" equivalent to that observed by Carol Gilligan with young girls. Gilligan and her colleagues 
described the way the safe, convinced and proud young girls "lose their voices" when they reach adolescence.

The first fully developed confrontation of gender inequality produces the gender gap that increases in adolescence. On the other hand, the boys become more confident, even beyond their capabilities, as girls grow less secure. Gender inequality means that when girls lose their voice, the boys find one - but it is an unauthentic voice of rejoicing, constant posing, the ridiculous undertaking of risk and unnecessary violence.

The society expects the boys to be with power and in this way to begin to behave like this because they are aware of the expectations of society. Although the girl's voices are helpless, boy's voices are raspy and full of bounce. But their voices are disconnected from their true feelings, how we educate boys, makes them wear the "Masculinity Mask", a pose, a facade. They "wrinkle" in a manly attitude. The girls "lose their voice" means that girls are more likely to underestimate their abilities, especially in traditionally "masculine" educational areas like math and science and traditionally "masculine" fields of employment such as medicine, military or architecture. Only the most capable and confident woman take these courses or follows these career path. Therefore their number tends to be small and their grades high. The boys, however, possessing the voice of false bounce (and very strong family pressure to enter in traditionally masculine fields), are more likely to overestimate their abilities, to stay in the program even though they are less qualified and able to succeed. In a recent study, the sociologist Shelley Correll compared thousands of eighth graders in similar academic path with identical grades and test scores. Boys were more likely to remember, their scores and grades were identical - to say, "I was always good in math" and "Mathematics is one of my best subjects" compared with girls. The boys were not better than girls - they just thought they were.

This difference and not an alleged discrimination against boys is why the average test scores of girls in mathematics and science are now, on average, close to those of boys. Many boys who overestimate their skills stay in mathematics and science courses longer than necessary; this reduces the average results of the boys. In contrast, few girls, the skills and self-esteem of which are sufficient to enable them to "enter without permission" in a masculine field, upward female data.

It is not the school experience what "feminize" boys, but more the ideology of traditional masculinity that prevents boys from the desire to succeed.

And the efforts to make the class more secure and more welcoming for girls have also contributed in favor of boys. The main problems identified by the high school teachers were initially (in order): speaking without queue, gum, doing noise, running in the hall, the separation of the row, the violation 
of the dress code and waste disposal. After 1990, the main disciplinary problems were (again, in order), drug use, alcohol use, pregnancy, suicide, rape, robbery and assault. The challenging stereotypes, the decline in tolerance for school violence and bullying decline make the boys and girls to feel safe in school. They simply raise their hands in resignation and sigh that "boys will be boys" will believe that nothing can or should be done to make those classes safer. To my mind, those four words, "boys will be boys" may be the most depressing words in the education policy circles today.

"The Battle of genders" is not a zero-sum game - whether played in our schools, our jobs or in our homes. Women and men, girls and boys will benefit from true gender equality in schools. Gender equality in schools is a benefit for the whole society.

The school environment influences the gender differentiation through two sources: teachers and peers. Teachers have a direct impact on the gender difference in the way how they differ boys and girls in the process of opportunities offered to them and the way of evaluation. Teachers use the curriculum that uses gender stereotypes behaviours and peers manifest this behavior and attitude of gender stereotypes. The children internalize gender stereotypes and turn them in preference and common attitudes.

Teachers contribute to the development of gender stereotypes. Often teachers during teaching in class perform stereotypical gender behavior. Women teachers can exhibit behaviors about phobia for mathematics. Teachers have often different expectations for male and female students. Teachers facilitate children's gender biases by marking gender as important by using it to label and organize students.

Peers affect the socialization of gender differences in different ways. At the moment when the child begins school, he meets with many of his peers, many of whom behave according to traditional gender roles thus reenforcing gender stereotypes. Peers also use punitive verbal and non-verbal behaviors against those students who did not meet the expectations of gender roles, for example, long hair are for girls and not for boys. While "bad girls" are considered those who do not apply behaviours pursuant to the expectations of teachers. Girls are more open to new ideas, boys are closer. Girls are more controlled while boys are out of control and reckless.

In many countries, teachers still continue to use sexist language when communicating with students.

The continuous findings have shown that boys have more opportunities to interact with teachers, dominate the various activities that take place in school and have more attention than girls when criticized or assisted. The discipline in the classroom is almost a silent practice that reflects the attitudes of the teachers where traditional values about femininity and masculinity are reinforced. 
In general, teachers believe they do not take into account the gender of the students when they explain and announce that they see students as children, they do not see them as boys or girls. However, in practice, teachers use some behaviors that favor boys and some behaviors that favor girls. Teachers give assignments to reinforce gender expectations in children. Teachers continue to see girls as successful only trying hard while the boys as naturally smart.

Although most teachers believe they give equal treatment to girls and boys in the support of their learning, focus group interviews with students and classroom observations of teacher-student interactions showed a balanced treatment is rarely achieved. Boys dominated certain classroom interactions while girls participated more in teacher-student interactions that supported learning. Boys felt they received more negative attention from teachers; indeed, they were reprimanded more and asked fewer questions to solicit their teachers' help. Girls asked more academic questions, focusing on understanding of subject knowledge, content, and concepts.

\section{Conlusion}

- $\quad$ The school is the second institution, after the family that influences the process of socialization.

- In the process of socialization in schools teachers and peers have an influence.

- $\quad$ Teachers have stereotype behaviours regarding the attitudes towards both sexes.

- $\quad$ Assessments of teachers for the duties of girls and boys differ, boys are valued for skills, intellectual levels while girls for the form and presentation.

- The teachers connect the progress of girls with their great efforts, while the progress of boys with the fact that they are naturally smarter.

- In case of failure for boys they think that they have not used the maximum of intellectual skills that they possess.

- $\quad$ Girls are expected to be polite while boys to be oblivious.

- $\quad$ The school and teachers are institutions that can and should govern and possess the gender education to all meanings.

- $\quad$ It is important to look at all school curricula and to be prioritized the gender education.

- In our country, the female students constitute the largest number of students in social sciences, incentive policies should be taken to change this ratio.

- $\quad$ Schools can magnify or diminish gender differences by providing environments that promote within-gender similarity and between-gender 
differences, or the inverse (within-gender variability and between group similarity)

- Unfortunately, teachers receive relatively little training in recognizing and combating gender stereotypes and prejudices, these trainings are very important

- $\quad$ Parents should seek educational settings for their students that are gender integrated and that make use of curricula that directly teach about, and challenge, gender bias and inequality.

\section{References:}

Kaplan, P. S. (2000). A Childs Odyssey: Child \& Adolescent Development (3rd ed.) USA: Wadsworth.

Jackson, C. \& Warin, J. (2000). The importance of gender as an aspect of gender identity at key transition points in compulsory education. British Educational Research Journal, 26, 375-389.

Katsurada, E. \& Sugihara, Y. (2002). Gender- role identity, attitudes towards marriage and gender segregated backgrounds. Sex Roles, 47, 249-258.

Bandura, A.Ross. D\& Ross. S. A (1961). Transmission os aggression through the imitation of aggressive models. Journal of Abnormal and Social Psychology, 63, 575-582

Duru-bellat M., L'ecole des filles. Quelle formation pour quels roles sociaux?, Paris, L’Harmattan, 1990

\section{Weblography}

http://www.businessdictionary.com/definition/socialization.html

http://anthro.palomar.edu/social/soc_1.htm

https://www.boundless.com/sociology/textbooks/boundless-sociology-

textbook/gender-stratification-and-inequality-11/gender-and-socialization-

86/gender-socialization-495-3393/

http://www.education.com/reference/article/gender-roles-schools/

http://eujournal.org/index.php/esj/article/viewFile/3802/3618 